\title{
SURVEY OF THE LEVEL OF AWARENESS AMONG ADOLESCENTS OF SEXUALLY TRANSMITTED DISEASES AND WAYS TO PREVENT THEM
}

\author{
Violeta Aleksieva, Ivan Dimitrov, Ivan Aleksandrov \\ Department of Health Care, Sliven Affiliate, \\ Medical University of Varna
}

\begin{abstract}
In the last few years, there has been a decrease in the age when adolescents first start their sexual lives. What is more, there is insufficient awareness about sexually transmitted diseases and unwillingness to observe good sexual health amongst adolescents. Quite often the control of parents, school teachers and community is also insufficient and that causes potential dangers. Some of these issues are contracting sexually transmitted diseases, unwanted pregnancy and abortions. This provokes the search for adequate means for the formation of values in adolescents in regard to good sexual and reproductive health.

AIM: Establishing the level of knowledge among adolescents about the ways of how sexually transmitted diseases are contracted and how to prevent them.

MATERIALS AND METHODS: During the period between September and December 2015, an anonymous survey was conducted among 145 students between the ages of 15 and 19 from the cities of Sliven and Tvarditsa.

RESULTS: In regard to the knowledge of the ways of transmission of sexually transmitted diseases, the highest awareness level was the one about AIDS - 93.8\% and the one about syphilis - 71.7\%. Knowledge regarding the transmission of HIV/AIDS was extremely high: $91 \%$ of the surveyed indicated that AIDS is transmitted through sexual contact without the use of a condom and $93 \%$ of the surveyed are adamant about the necessity of condoms. The surveyed students indicated that they gathered their information about sexually transmitted diseases mainly from the Internet-73.8\%, followed by health education materials- 52\%.
\end{abstract}

CONCLUSIONS: The highest level of knowledge is about AIDS and syphilis. There is enough motivation for the use of condoms and it should be maintained over time. Information gathered through the Internet replaces sexual education as the main way of gaining knowledge in regard to sexually transmitted diseases.

Keywords: sexually transmitted diseases, level of knowledge, prevention

Address for correspondence:

Violeta Aleksieva

Department of Health Care, Sliven Affiliate

Medical University of Varna

30 General Stoletov St.

Sliven

e-mail: aleksieva_1968@abv.bg

\section{INTRODUCTION}

In recent years, there has been a decrease in the age of starting a sexually active life in adolescents. Along with this, there is insufficient awareness about sexually transmitted diseases and disregard of sexual health. Often, the control by parents, teachers in the 
school and community is inadequate, which creates a number of potential hazards. Among them are sexually transmitted infections, unwanted pregnancy and abortions. This has provoked the demand for adequate mechanisms for formation of values regarding adolescent sexual and reproductive health (1).

\section{AIM}

The aim of this study was to determine the level of awareness among teenagers about the pathways of sexually transmitted infections and how to prevent them.

\section{MATERIALS AND METHODS}

A survey was conducted among 145 students aged 15-19 from the towns Sliven and Tvarditsa, during the period September - December 2015.

\section{RESULTS AND DISCUSSION}

The opinion of 145 students from different age groups and gender was studied in the period Septem- portional to the level of awareness of the consequences of keeping a promiscuous sex life.

In terms of first sexual intercourse: it is a fact in $54.6 \%$ of cases, but had not yet taken place in $45.4 \%$ of respondents (Fig. 1). The age of first intercourse, as reported by participants, is presented on Figure 2 .

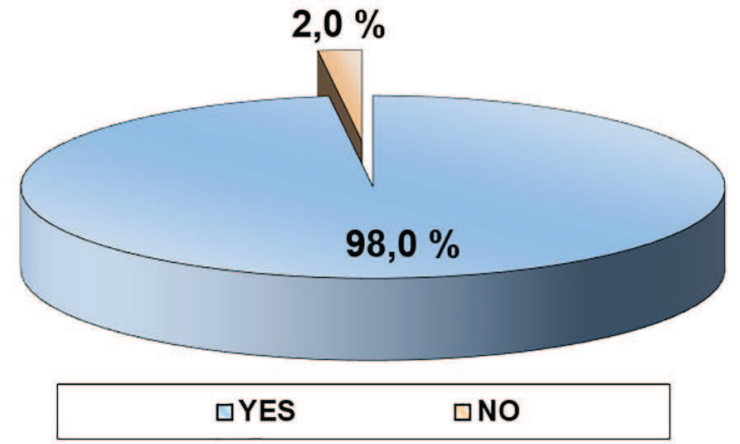

Figure 2. Distribution of pupils' opinions about the age of their first sexual intercourse

Table 1. Distribution of students by age.

\begin{tabular}{lccccc} 
Age & 15 years & 16 years & 17 years & 18 years & 19 years \\
\hline Share in\% & $14.5 \%$ & $14.5 \%$ & $30 \%$ & $37 \%$ & $4 \%$ \\
\hline
\end{tabular}

ber-December 2015. Age distribution of the respondents is presented in Table 1.

In terms of gender, $61 \%$ of participants are girls and $39 \%$ are boys.

In recent years, the lower age limit of sexual intercourse has dropped dramatically, inversely pro-

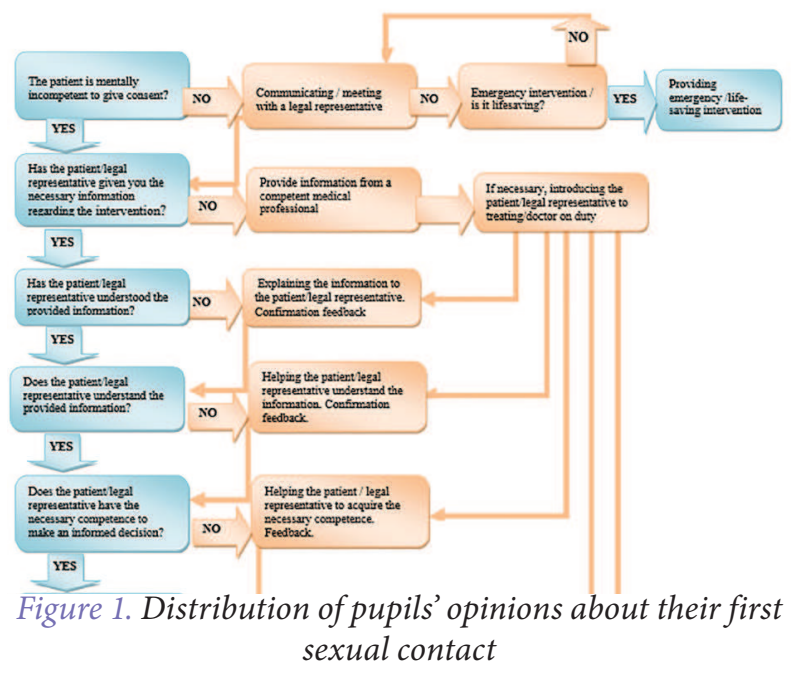

These data coincide with the study of the Family Planning Association in Bulgaria, where it was found that adolescents begin to have sexual relations at about 15 years of age (2).

Sexually transmitted diseases are a group of diseases with different causes; some are treatable, while others present a continuous challenge for medical science. Prevention is part of the rules for safer sex and responsibility for sexual health in order to manage the new cases, about 250 million each year

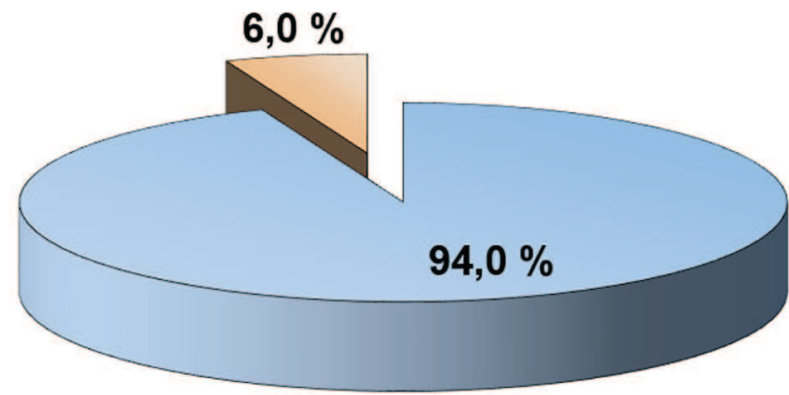

Figure 3. Distribution of the opinion of respondents on their awareness on sexually transmitted diseases 
Violeta Aleksieva, Ivan Dimitrov, Ivan Aleksandrov

(3). In terms of the knowledge of the ways of transmission of sexually transmitted infections, the highest awareness is of AIDS - 93.8\% and syphilis - 71.7\%. Knowledge regarding genital herpes is $38.6 \%$, gonorrhea $-37.9 \%$, fungal infections $-34.5 \%$ and hepatitis B - 20.7\% (Figure 3).

The main source of infection of sexually transmitted diseases are humans (4). Knowledge regarding the transmission of HIV/AIDS is extremely high: $91 \%$ of respondents indicated that the AIDS virus is transmitted through vaginal and anal sex without a condom. Transmission through blood (when sharing needles, syringes and other materials for drug injection) is known to $75 \%$ of the respondents. About $63 \%$ know the risks of blood transfusion from a person who is HIV positive. About $49 \%$ of respondents know the possibility of transmission from an HIVpositive mother to her newborn (Figure 4).

Important are the answers to questions concerning protection against sexually transmitted infections. To the question: "What means for the pre-

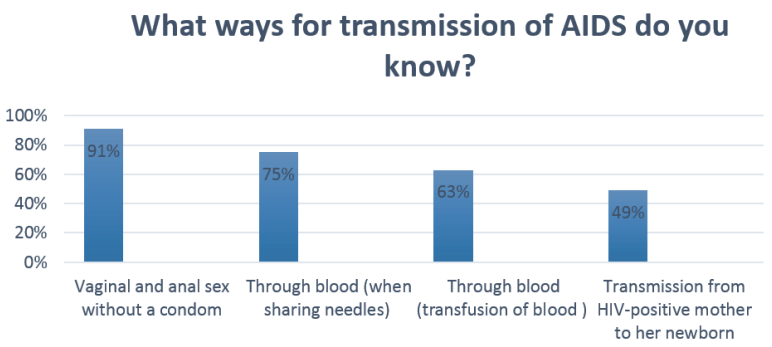

Figure 4. Distribution of the opinion of respondents on their awareness of AIDS transmission

vention against sexually transmitted diseases do you know?", 93\% of respondents are aware of the need to use a condom. For about $6 \%$ the solution is abstinence from sexual intercourses, and for 35\% - the relationship with only one partner (Figure 5).

Young people seek knowledge regarding sexually transmitted infections from various sources. Respondents indicated that they obtained knowledge from the Internet - 73.8\%, from health education materials - $52 \%$, from the family - $45.3 \%$, from media $25 \%$, from school $-45.5 \%$, and from medical professionals - 23\% (Figure 6).

The highest level of knowledge is about AIDS and syphilis. The ways of transmission of HIV/AIDS
What ways to prevent sexually transmitted diseases do you know?

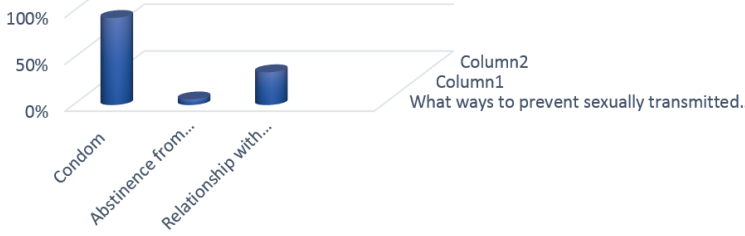

Figure 5. Distribution of the opinion of respondents on how to prevent sexually transmitted diseases

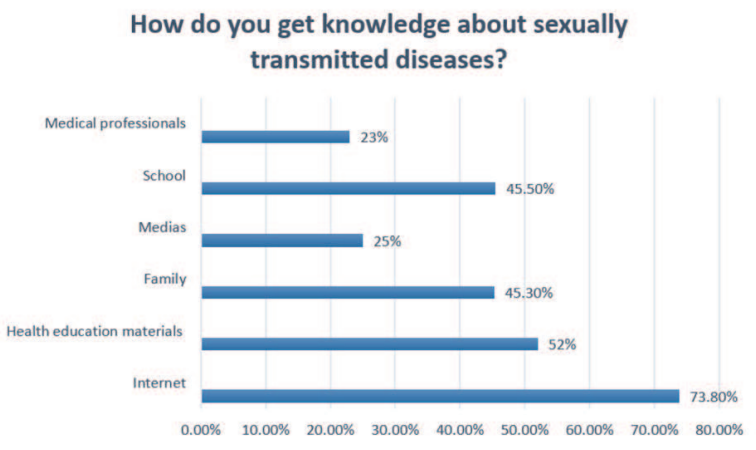

Figure 6. Distribution of the opinion of respondents on the sources of information about sexually transmitted diseases

are well known. The motivation for condom use is properly oriented and should be maintained in the future. The main sources for gathering information are the Internet and social networks. They are easily accessible, but insufficiently secure and incomplete. They tend to replace health education as a means of obtaining information on sexually transmitted infections, which is an intimidating fact.

\section{CONCLUSION}

Our study shows some trends in the field of health education, which would improve health knowledge, attitudes and skills for risky sexual behavior.

The formation of knowledge among adolescents is a complex problem. Early and timely sexual education would significantly increase the level of knowledge about sexually transmitted diseases. 


\section{REFERENCES}

1. Serdyuk E. Actual problems of modern pedagogy, materials, VI International Learn. Conference, Ufa, 2015, 139-141.

2. National representative survey of sexual and reproductive health of young people from the Ministry of Health, ESTAT, 2009.

3. Ministry of Health, Regional Health Insurance Institute- Sliven.

4. HIV/AIDS and STIs among young people in Bulgaria Ministry of Health, National Center of Public Health, Sofia. 